\title{
Preparation and properties of porous carbon material containing magnesium oxide
}

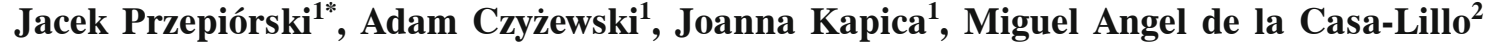 \\ ${ }^{1}$ West Pomeranian University of Technology in Szczecin, Institute of Chemical and Environmental Engineering, ul. Putaskiego 10, \\ 70-322 Szczecin, Poland \\ ${ }^{2}$ Universidad Miguel Hernández, Instituto de Bioingeniería, Edificio Vinalopo, Avda. de la Universidad s/n, 03202-Elche, \\ Alicante, Spain. \\ *Corresponding author: e-mail: jacek.przepiorski@zut.edu.pl
}

\begin{abstract}
Porous carbons loaded with magnesium oxide were prepared through one-step process. Poly(ethylene terephthalate) and natural magnesite were used as carbon source and $\mathrm{MgO}$ precursor, respectively. An impact of a temperature and relative amounts of raw components used for preparations on the textural parameters of resulting hybrid materials is presented and discussed. As found, pore structure parameters tend to decrease along with $\mathrm{MgO}$ loading and temperature used during preparation process. Micropore area is the parameter being reduced primarily.
\end{abstract}

Keywords: porous carbon, $\mathrm{MgO}$, porosity.

\section{INTRODUCTION}

In recent years there has been a rapid progress in many industries, particularly in the manufacture of advanced devices based on semiconductors, pharmaceuticals, or in biotechnology. One of the key factors regularly required to carry out production processes with the advanced processes is a purity of the technological media, including air. This requires utilization of effective filtering devices capable to remove from large volumes of the air impurities to achieve desired levels. Apart from the technology, purification of air is often employed in large air conditioning systems and very specific case like personal gas masks can be also considered as examples of small air purification systems.

Currently, despite solid particulates, elimination of gaseous pollutants present in the air even in trace amounts is often necessary ${ }^{1}$. For that reason, new and cheap methods and materials for effective purification of gases are being constantly developed. Air filters regularly use activated carbons. Both efficiency and selectivity of these adsorbents can be modified by a proper chemical treatment or by loading suitable chemicals intentionally chosen to remove specific gases from the $\mathrm{air}^{2-5}$. In this way so called chemical filters are manufactured. Thus, in addition to the physical adsorption, a chemisorption involving a chemical reaction between the chemical and pollution may play an important role ${ }^{6,7}$. Carbon sorbents loaded with chemicals are typically produced through impregnation of activated carbon with suitable organic or inorganic compounds, carefully selected for specific applications ${ }^{\mathbf{8}, \mathbf{9}}$. For example, highly efficient removal of acid gases such as $\mathrm{SO}_{2}$ and $\mathrm{CO}_{2}$ exhibit porous carbons loaded with bases like $\mathrm{NaOH}, \mathrm{KOH}$, or $\mathrm{K}_{2} \mathrm{CO}_{3}{ }^{10}$. Despite impregnation, carbon adsorbents loaded with additives can also be prepared by so called blending method, consisting in thermal treatment of carbon precursor with a precursor of an additive ${ }^{11}$.

An analysis of the literature clearly indicated lack of reports on the activated carbons loaded with magnesium oxide, produced according to the blending method. However, there are two well-known industrial methods for $\mathrm{SO}_{2}$ removal from flue gas, the magnesite method and the Bergbau-Forschung method, employing $\mathrm{MgO}$ and activated coke, respectively. For that reason, development of a new material combining some features of the coke and $\mathrm{MgO}$, seemed to be reasonable. Possible application spectrum of such hybrid material can be potentially extended to other gases. For instance, activated carbons containing $\mathrm{MgO}$ obtained by the impregnation method were reported to be capable to capture $\mathrm{CO}_{2}$ gas $^{12-14}$. Effective acid gas adsorption on other materials containing $\mathrm{MgO}$ was also reported ${ }^{15-17}$.

Magnesium oxide is a chemical capable to create mesopores in a char formed up during pyrolysis of carbon precursors with $\mathrm{MgO}$ or its precursor ${ }^{18,19}$. It was also confirmed ${ }^{20}$ that the carbonization of the mixture of poly(ethylene terephthalate) (PET) with a basic magnesium carbonate $\left[3 \mathrm{MgCO}_{3} \cdot \mathrm{Mg}(\mathrm{OH})_{2} \cdot 3 \mathrm{H}_{2} \mathrm{O}\right]$ results in obtaining porous carbon material rich in both mesopores and micropores. Here, formation of mesopores was mainly due to $\mathrm{MgO}$ presence and micropores were created during reaction between a char formed from PET and gases, $\mathrm{CO}_{2}$ and $\mathrm{H}_{2} \mathrm{O}$, formed during thermal decomposition of the carbonate.

The aim of this study was to develop a simple method for obtaining new carbon sorbent containing $\mathrm{MgO}$, from readily available and economically attractive raw materials. Hence, PET was chosen as carbon source and natural magnesite served as $\mathrm{MgO}$ precursor and $\mathrm{CO}_{2}$ delivering agent. Potentially, both products formed from the magnesite may act as pore generating agents.

\section{EXPERIMENTAL}

\section{Materials}

Poly(ethylene terephthalate) used as carbon precursor was of commercial grade, purchased from Elana S.A., Poland. Another raw material, magnesite, was a mineral mined from deposits located near Grochów, Poland and obtained from Magnezyty Grochów S. A., Poland. According to the product data sheet obtained from the supplier, magnesium carbonate is a main component in the mineral. The weight contents of all the major components naturally present in the magnesite, with reference 
to oxides, are as following: $\mathrm{MgO} 30-38 \%, \mathrm{SiO}_{2} 14-23 \%$, $\mathrm{Fe}_{2} \mathrm{O}_{3} 4-6 \%$, and $\mathrm{CaO} 1-2.5 \%$. High purity (99.999\%) argon gas used during preparations was purchased from Messer, Austria.

\section{Preparations}

Carbon materials containing magnesium oxide $(\mathrm{MgO})$ were prepared through pyrolysis of a mixtures consisting of poly(ethylene terephthalate) (carbon source) and the magnesite ( $\mathrm{MgO}$ precursor). $20 \mathrm{~g}$ of finely ground PET was mechanically mixed with $8.6 \mathrm{~g}$, or $20.0 \mathrm{~g}$, or $46.0 \mathrm{~g}$ of the pulverized magnesite. In this way mixtures of PET/ magnesite, hereinafter signed as PET/MAG, at weight ratios 70:30, 50:50, and 30:70, were obtained, respectively. The mixtures were preheated in argon flow $\left(100 \mathrm{~cm}^{3} /\right.$ $\mathrm{min})$ at $538 \mathrm{~K}$ for 1 hour. The sintered materials obtained were finely ground, and then in portions heated under flowing argon from room temperature to $923 \mathrm{~K}, 1023 \mathrm{~K}$ or $1123 \mathrm{~K}$. The final temperature was maintained for 1 hour. In each case heating rates were $10 \mathrm{~K} / \mathrm{min}$.

For reference, $\mathrm{MgO}$-free carbons were prepared from obtained hybrid materials. For that purpose, $\mathrm{MgO}-$ loaded materials prepared according to procedure described above were washed with excessive amounts of 3.2 $\mathrm{M} \mathrm{HCl}$. After 24 hours long stirring remained solid was separated from the suspension and washed with portions of distilled water until constant $\mathrm{pH}$ was achieved. After final filtration, the solid carbonaceous product was dried in air at $383 \mathrm{~K}$ for 24 hours.

\section{Methods}

Parameters of pore structure for the obtained materials were determined on the base of nitrogen adsorption measurements at $77 \mathrm{~K}$. The nitrogen adsorption/desorption isotherms for individual materials were measured with use of Quadrasorb SI analyser (Quantachrome Instruments). 12 hours long degassing at $563 \mathrm{~K}$ under high vacuum was carried out for each sample prior to the adsorption measurements. Specific surface area values were determined by applying BET method. Micropore surface areas $\left(\mathrm{S}_{\text {micro }}\right)$, external surface areas $\left(\mathrm{S}_{\text {ext }}\right)$, and total surface areas $\left(\mathrm{S}_{\text {total }}\right)$ were calculated applying the as method.

Thermogravimetric analyses were carried out on a Netzsch STA 449 C thermobalance. For this purpose, samples of PET/MAG $(10 \mathrm{mg})$ raw mixtures were heated from $298 \mathrm{~K}$ to $1223 \mathrm{~K}$ at a heating rate of $10 \mathrm{~K} / \mathrm{min}$ under $\mathrm{N}_{2}$ atmosphere $\left(30 \mathrm{~cm}^{3} / \mathrm{min}\right)$. In order to estimate content of inorganics, i.e. $\mathrm{MgO}$ and eventual impurities, in obtained samples, additional thermogravimetric analyses were carried out in air atmosphere $\left(30 \mathrm{~cm}^{3} /\right.$ min) applying the same temperature program.

\section{RESULTS AND DISCUSSION}

\section{Thermogravimetric studies}

An example of thermogravimetric analysis of PET/ MAG mixture, together with thermograms measured for the components individually is presented in Fig. 1.

During heating the of the PET/MAG mixture, two distinct mass drops occur. The first one with a maximum rate at $706 \mathrm{~K}$ is close to that seen for pure PET (Fig. 1b). The second distinct mass drop occurs at ca. $870 \mathrm{~K}$. Taking into account TG gram measured for the magnesite alone, it may be stated that this drop is related to the thermal decomposition of the mineral contained in a raw mixture. The mass of the sample gets stabilized at ca. $920 \mathrm{~K}$.

Thermogravimetric analyses performed for the mixtures prepared at different weight ratios confirmed proceeding of analogous changes during heating. Naturally, because of different loadings of magnesite, residual masses registered at the end of measurements were different and increased along with magnesite content. The insignificant mass decrement observed at above $900 \mathrm{~K}$ must be resulting from a slow reaction between carbonaceous material formed from PET, and $\mathrm{CO}_{2}$ gas released from magnesite. This effect had been extensively studied in our previous works $^{\mathbf{2 0 , 2 1}}$, dealing with pyrolysis of PET in mixtures with other decomposable magnesium compounds.

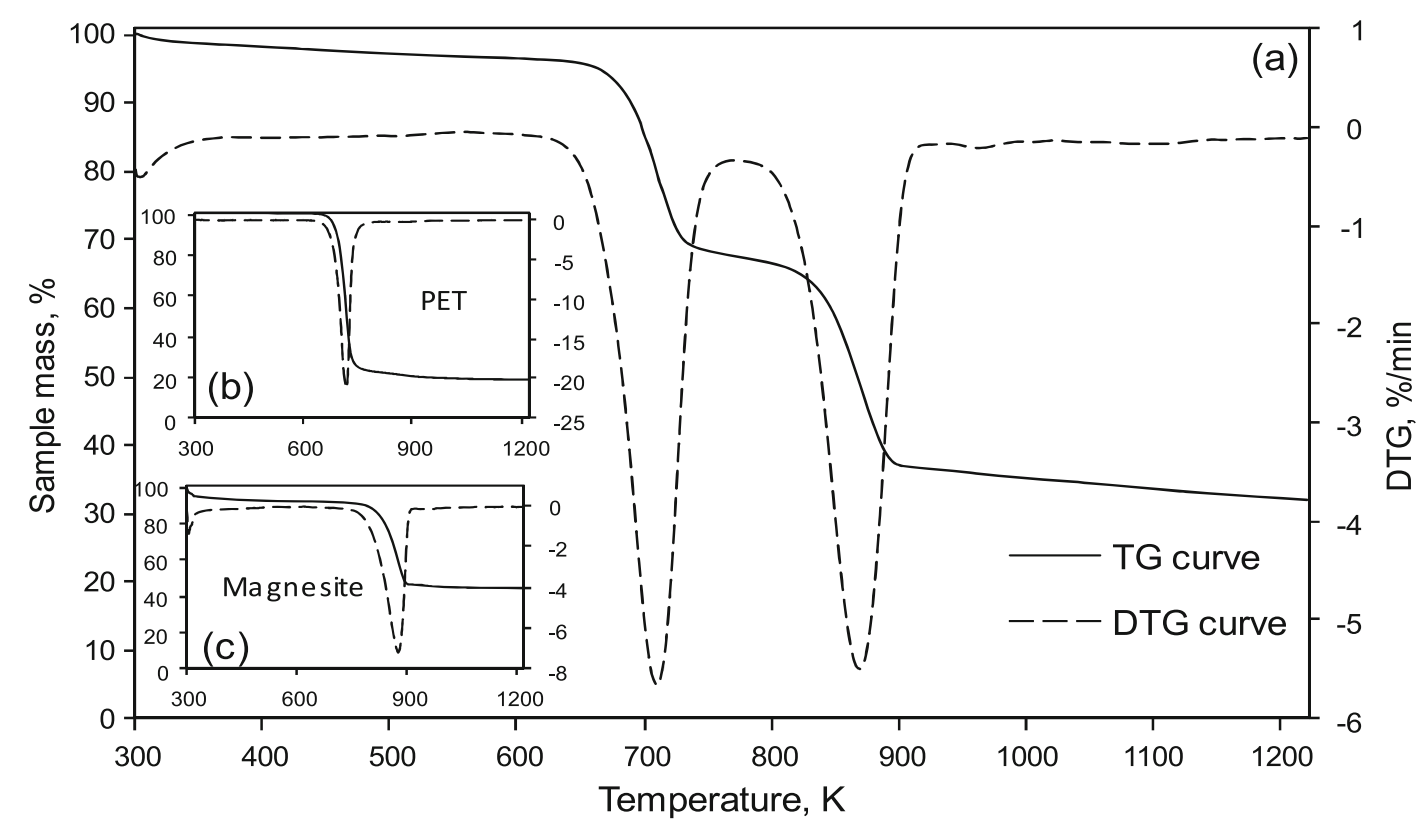

Figure 1. Thermogravimetric analysis of a) raw PET/MAG mixture (50:50) and TG-grams measured for PET b) and raw magnesite c) 


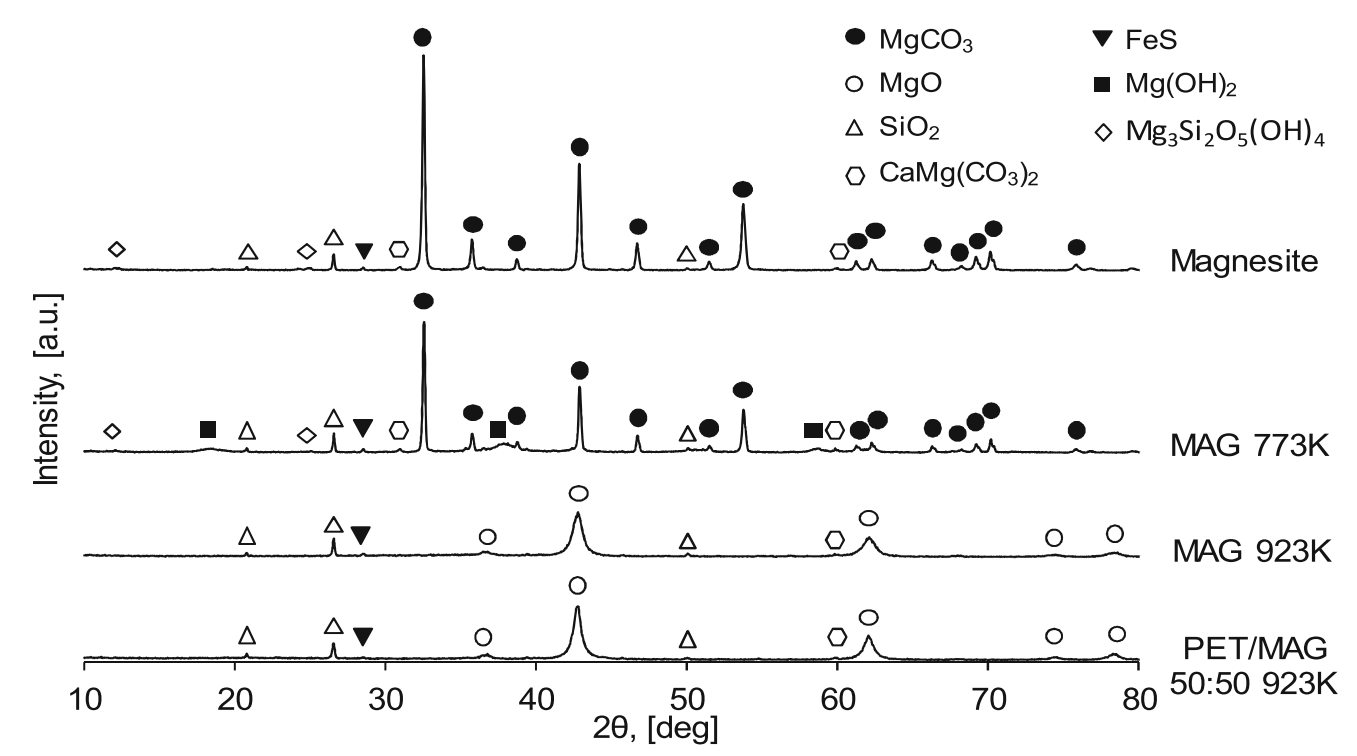

Figure 2. X-ray diffraction patterns for magnesite (raw and heated to $773 \mathrm{~K}$ and $923 \mathrm{~K}$ ) and PET/MAG mixture (50:50) after heating to $923 \mathrm{~K}$

$\mathrm{X}$-ray diffraction and phase composition of the prepared materials

X-ray diffraction patterns for the magnesite (raw and subjected to heating to $773 \mathrm{~K}$ and $923 \mathrm{~K}$ ), and for PET/ MAG (50:50) pyrolysed at $923 \mathrm{~K}$, are shown in Fig 2.

Obviously, the main phase recognized in the hybrid material after pyrolysis, $\mathrm{MgO}$, is formed from $\mathrm{MgCO}_{3}$ contained in the mineral. Despite the oxide, the product contains small amounts of contaminants, also originating from the magnesite. Equivalent results could be obtained for materials prepared at other temperatures (i.e. at 1023 $\mathrm{K}$ or $1123 \mathrm{~K}$ ) and using different weight ratios of raw materials. Taking into account results of XRD analyses
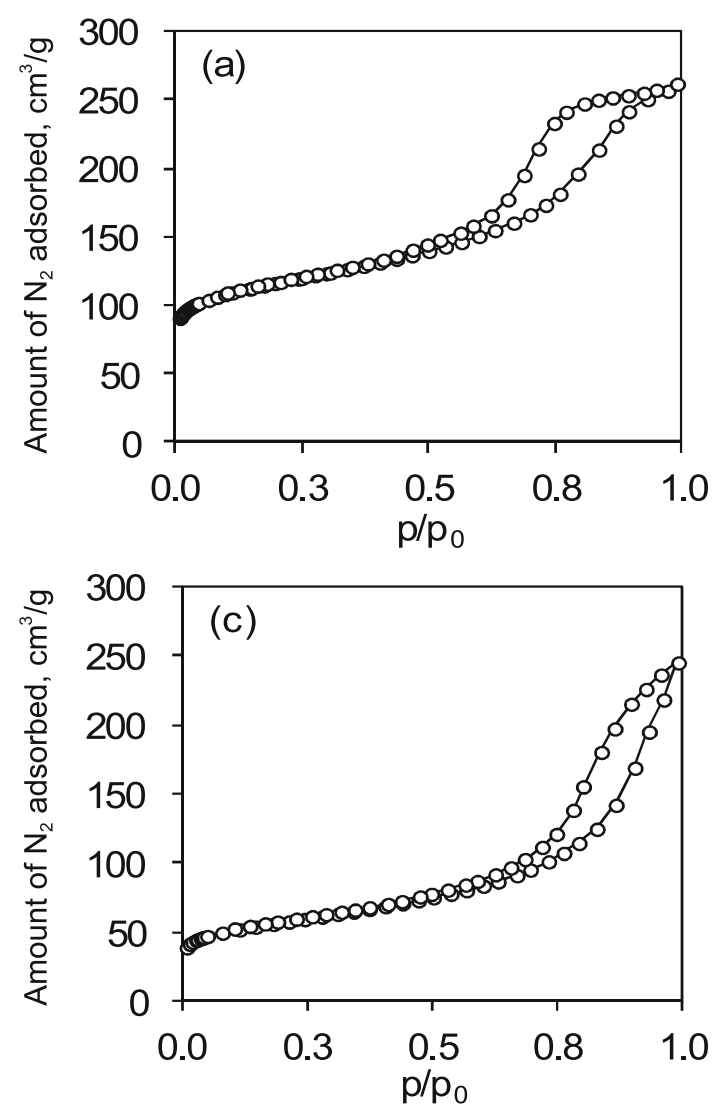

and TG measurements (Fig. 1) we postulate that in order to obtain carbon material loaded with magnesium oxide via pyrolysis of PET/MAG mixture, a treatment temperature of at least ca. $920 \mathrm{~K}$ is required. The lower temperature may be not enough to decompose $\mathrm{MgCO}_{3}$ to the oxide.

\section{Porosity of the materials}

$\mathrm{N}_{2}$ adsorption/desorption isotherms measured for the prepared samples containing $\mathrm{MgO}$ are of similar shape. Typical examples are presented in Fig 3.

Characteristic knees seen at the low relative pressures, like in type I isotherm according to IUPAC classification,
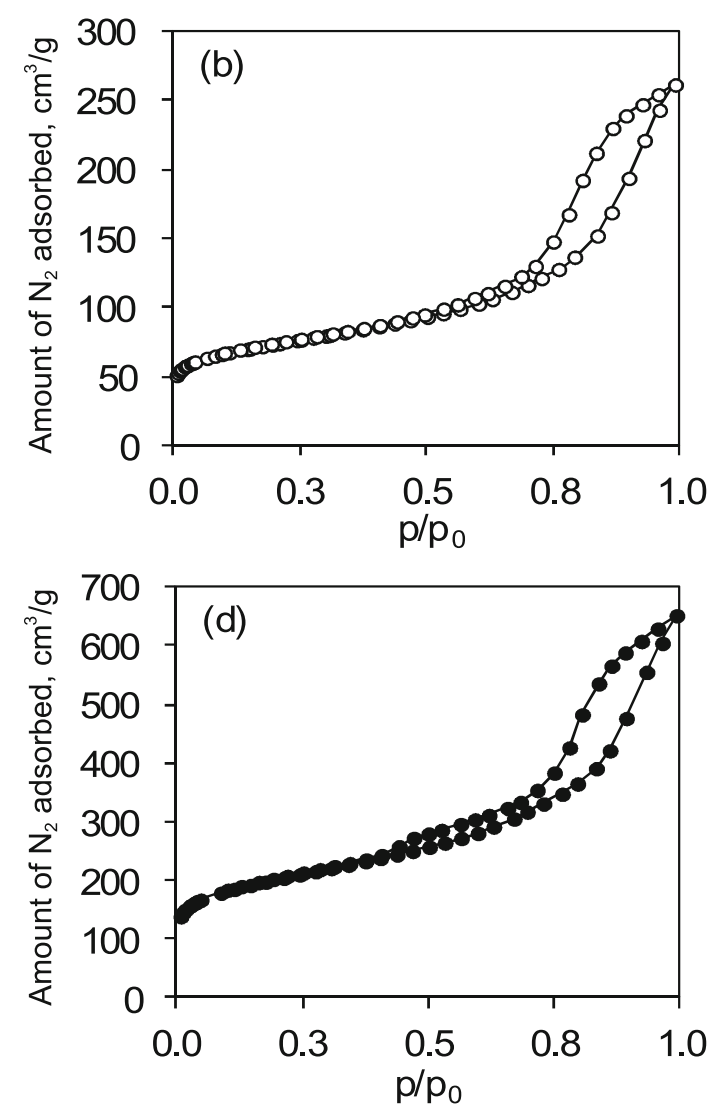
Table 1. Structure parameters of PET/MAG 50:50 ratio composite materials prepared in different temperatures

\begin{tabular}{|c|c|c|c|c|c|c|}
\hline \multirow{2}{*}{$\begin{array}{l}\text { PET/MAG } \\
\text { weight ratio }\end{array}$} & \multirow{2}{*}{$\begin{array}{l}\mathrm{MgO}^{*} \text { content in } \\
\text { the product } \\
\text { [wt. \%] }\end{array}$} & \multirow{2}{*}{$\begin{array}{l}\text { Preparation temperature } \\
\qquad[\mathrm{K}]\end{array}$} & \multirow{2}{*}{$\begin{array}{c}\mathrm{S}_{\mathrm{BET}} \\
{\left[\mathrm{m}^{2} / \mathrm{g}\right]}\end{array}$} & \multicolumn{3}{|c|}{$\alpha_{\mathrm{S}}$ method } \\
\hline & & & & $\begin{array}{c}S_{\text {total }} \\
{\left[\mathrm{m}^{2} / \mathrm{g}\right]}\end{array}$ & $\begin{array}{c}S_{\text {ext }} \\
{\left[\mathrm{m}^{2} / \mathrm{g}\right]}\end{array}$ & $\begin{array}{l}S_{\text {micro }} \\
{\left[\mathrm{m}^{2} / \mathrm{g}\right]}\end{array}$ \\
\hline $50: 50$ & 65 & 923 & 240 & 279 & 136 & 143 \\
\hline $50: 50$ & 65 & 1023 & 195 & 219 & 109 & 110 \\
\hline $50: 50$ & 65 & 1123 & 188 & 205 & 118 & 87 \\
\hline $70: 30$ & 53 & 923 & 370 & 480 & 160 & 320 \\
\hline $50: 50$ & 65 & 923 & 240 & 279 & 136 & 143 \\
\hline $30: 70$ & 78 & 923 & 206 & 223 & 115 & 68 \\
\hline $\begin{array}{l}\text { 50:50 } \\
\text { (acid washed) }\end{array}$ & 0 & 923 & 694 & 754 & 382 & 372 \\
\hline
\end{tabular}

confirm presence of considerable amounts of micropores. On the other hand, the characteristic hystereses at relative pressures above 0.4 , like in type IV isotherms, testify capillary condensation in mesopores. As a rule, certain decrease in the amount of nitrogen adsorbed can be seen along with magnesite loading in a raw mixture, and thus with $\mathrm{MgO}$ loading in a product. Adsorption of nitrogen decreases slightly also along with final temperature used during preparation of a material. The pore structure parameters calculated from the obtained isotherms are listed in Tab. 1.

From the data contained in Tab. 1. it is evident that BET and the total specific surface area tend to decrease along with both preparation temperatures and with $\mathrm{MgO}$ loadings in the obtained products. Considering other results of $\alpha_{S}$ analysis, the decrease is resultant from lowering of micropore area and external surface area. Taking into account significantly higher parameters determined for acid washed, i.e. $\mathrm{MgO}$ - free, sample, it may be stated that relatively low porosity of $\mathrm{MgO}$ - containing materials studied in this work is because of $\mathrm{MgO}$ presence. Similar effect of inorganic additives on porosity of carbons we have already reported elsewhere ${ }^{20,21}$. From the data presented some practical indications can be drawn. Hence, in order to achieve a high specific surface area of a product, it is advised to carry out preparations at possibly low final temperature. But, the temperature should be high enough to assure thermal decomposition of the magnesite to the desired $\mathrm{MgO}$. An influence of $\mathrm{MgO}$ content on pore structure parameters is different factor. Hence, even higher loadings of this compound may result in obtaining materials revealing lower pore parameters, high $\mathrm{MgO}$ contents may be beneficial in some practical applications. For instance, high loadings of the oxide may increase performance of the hybrid sorbents in sorption processes where a chemical reaction between an adsorbate and the oxide takes place next to physisorption. Nevertheless, in order to evaluate if the high $\mathrm{MgO}$ loadings are beneficial or not, the materials must be first examined as a sorbent for specific adsorbates.

\section{CONCLUSIONS}

This work describes a simple process for preparation of porous carbon materials supporting $\mathrm{MgO}$. An important advantage of the method is that cheap $\mathrm{MgO}$ precursor, natural magnesite, can be used for preparations and the precursor plays a key role as a pore creating agent. Because of quite well-developed porosity and certain content the basic oxide, we believe that studied hybrid material can act as a material suitable for selective removal of certain impurities from gaseous streams.

\section{ACKNOWLEDGEMENTS}

This work was financed by the Polish Ministry of Science and Higher Education, grant N R050004 10.

\section{LITERATURE CITED}

1. Cambridge Filter Japan, Ltd. (2009). Product information. Received May 16, 2009, from http://www.cambridgefilter.com/ english/productsE/tcc-en/tcc-en.htm.

2. Liu, Z.-S. (2008). Adsorption of $\mathrm{SO}_{2}$ and NO from incineration flue gas onto activated carbon fibers. Waste Manage., 28, 2329-2335. DOI:10.1016/j.wasman.2007.10.013.

3. Aroua, M.K., Daud, W.M.A.A., Yin, C.Y. \& Adinata, D. (2008). Adsorption capacities of carbon dioxide, oxygen, nitrogen and methane on carbon molecular basket derived from polyethyleneimine impregnation on microporous palm shell activated carbon. Sep. Purif. Technol., 62, 609-613. DOI:10.1016/j.seppur.2008.03.003.

4. Houshmand, A., Wan Daud, W.M.A., \& Shafeeyan, M. S. (2011). Exploring Potential Methods for Anchoring Amine Groups on the Surface of Activated Carbon for $\mathrm{CO}_{2}$ Adsorption. Sep. Purif. Technol., 46, 1098-1112. DOI:10.1080/01496 395.2010.546383.

5. Zhang, Z., Ma, X., Wang, D., Song C. \& Wang, Y. (2011). Development of silica-gel-supported polyethylenimine sorbents for $\mathrm{CO}_{2}$ capture from flue gas. AIChE J., DOI:10.1002/ aic. 12771 .

6. Przepiórski, J., Yoshida, S. \& Oya, A. (1999). Structure of $\mathrm{K}_{2} \mathrm{CO}_{3}$-loaded activated carbon fiber and its deodorization ability against $\mathrm{H}_{2} \mathrm{~S}$ gas. Carbon, 37, 1881-1890. DOI:10,1016/ S0008-6223(99)00088-3.

7. Henning, K.D. \& Schäfer, S. (1993). Impregnated activated carbon for environmental protection, Gas Sep. Purif., 7, 235-240. DOI:10.1016/0950-4214(93)80023-P.

8. Hedin, N., Chen, L. \& Laaksonen, A. (2010). Sorbents for $\mathrm{CO}_{2}$ capture from flue gas-aspects from materials and theoretical chemistry. Nanoscale, 2, 1819-1841. DOI:10.1039/ c0nr00042f.

9. Wu, Z., Hao, N., Xiao, G., Liu, L., Webley, P. \& Zhao, D. (2011). One-pot generation of mesoporous carbon supported 
nanocrystalline calcium oxides capable of efficient $\mathrm{CO}_{2}$ capture over a wide range of temperatures. Phys. Chem. Chem. Phys., 13, 2495-2503. DOI:10.1039/c0cp01807d.

10. Przepiórski, J. (2006). Activated carbon filters and their industrial applications in Activated Carbon Surfaces in Environmental Remediation (Interface Science and Technology, Volume 7, ed. T.J. Bandosz, chapter 9, ISBN:0-12-370536-3, pp.421-474). Academic Press.

11. Przepiórski, J., Abe, Y., Yoshida, S. \& Oya, A. (1997). Preferential supporting of potassium carbonate around the peripheral region of activated carbon fiber. J. Mater. Sci. Lett., 16, 1312-1314. DOI:10.1023/A:1018599513817.

12. Yong, Z., Mata. V.G. \& Rodrigues, A.E. (2001). Adsorption of carbon dioxide on chemically modified high surface area carbon-based adsorbents at high temperature. Adsorption, 7, 41-50. DOI:10.1023/A:1011220900415.

13. Bhagiyalakshmi, M., Hemalatha, P., Ganesh, M., Peng, M.M. \& Jang, H.T. (2011). A direct synthesis of mesoporous carbon supported $\mathrm{MgO}$ sorbent for $\mathrm{CO}_{2}$ capture. Fuel, 90, 1662-1667. DOI:10.1016/j.fuel.2010.10.050.

14. She, L., Li, J., Wan, Y., Yao, X., Tu, B. \& Zhao, D. (2011). Synthesis of ordered mesoporous $\mathrm{MgO}$ /carbon composites by a one-pot assembly of amphiphilic triblock copolymers. J. Mater. Chem., 21, 795-800. DOI:10.1039/c0jm02226h.

15. Bhagiyalakshmi, M., Lee, J.Y. \& Jang, H.T. (20011). Synthesis of mesoporous magnesium oxide: Its application to $\mathrm{CO}_{2}$ chemisorption. Int. J. Greenh. Gas Con., 4, 51-56. DOI:10.1016/j.ijggc.2009.08.001.

16. Lee, S.J., Jung, S.Y., Lee, S.C., Jun, H.K., Ryu, C.K. \& J.C. Kim. (2009). $\mathrm{SO}_{2}$ removal and regeneration of $\mathrm{MgO}$ based sorbents promoted with titanium oxide. Ind. Eng. Chem. Res., 48, 2691-2696. DOI:10.1021/ie801081u.

17. Hassanzadeh, A. \& Abbasian, J. (2010). Regenerable $\mathrm{MgO}$-based sorbents for high-temperature $\mathrm{CO}_{2}$ removal from syngas: 1. Sorbent development, evaluation, and reaction modeling. Fuel, 89, 1287-1297. DOI:10.1016/j.fuel.2009.11.017.

18. Inagaki, M., Kobayashi, S., Koijn, F., Tanaka, N., Morishita, T. \& Tryba, B. (2004). Pore structure of carbon coated on ceramic particles. Carbon, 42, 3153-3158. DOI:10.1016/j. carbon.2004.07.029.

19. Inagaki, M., Kato, M., Morishita, T. Morita, K. (2007). Direct preparation of mesoporous carbon from a coal tar pitch. Carbon, 45, 1121-1124. DOI:10.1016/S1095-6433(98)00008-7.

20. Przepiórski, J., Karolczyk, J., Takeda, K., Tsumura, T., Toyoda, M. \& Morawski, A. M. (2009). Porous carbon obtained by carbonization of PET Mixed with basic magnesium carbonate: Pore structure and pore creation mechanism. Ind. Eng. Chem. Res. 48, 7110-7116. DOI:10.1021/ie801694t.

21. Przepiórski, J., Karolczyk, J., Tsumura, T., Toyoda, M., Inagaki, M. \& Morawski, A. W. (2011). Effect of some thermally unstable magnesium compounds on the yield of char formed from poly(ethylene terephthalate). J. Therm. Anal. Calorim. DOI:10.1007/s10973-011-1910-1. 